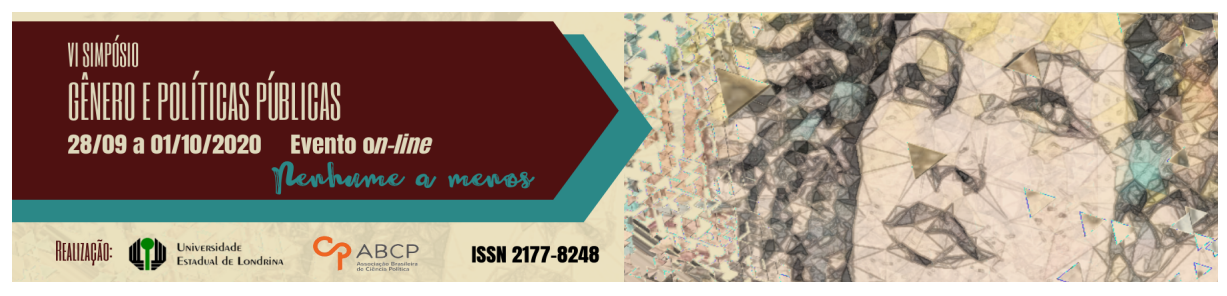

\title{
Discursos de alunos e alunas da educação básica quanto a gênero, ciência e fecundação humana
}

\author{
Andréa do Carmo Bruel de Oliveira ${ }^{1}$; Ana Paula Oliveira dos Santos ${ }^{2}$; \\ Bettina Heerdt ${ }^{3}$
}

\section{Resumo}

Análises de gênero na ciência evidenciam conhecimentos androcêntricos, que excluem e inferiorizam as mulheres, como no conteúdo de fecundação humana. No ensino de Ciências e Biologia discriminações de gênero podem ser reafirmadas. O objetivo da pesquisa é analisar o discurso de alunos/as da Educação Básica, ao representarem o processo de fecundação humana. A pesquisa é qualitativa, os dados provêm da investigação de Santos e Heerdt (2019), por meio da construção e aplicação de uma Unidade Didática (UD). A análise de discurso foi empregada, utilizando as epistemologias feministas para inferir seus significados. Os/as alunos/as visibilizam em seus discursos o processo de forma equânime, destacando ambos os gametas, citando aspectos de pesquisas recentes e contribuições do organismo feminino, discutidas durante a UD, porém recaem em estereótipos, ao representar a fecundação como casamento. Os discursos são controversos, no entanto, a possibilidade de transgredir aos conhecimentos impostos como verdade e criticados pelas epistemologias feministas aparecem nos discursos.

Palavras-chave: epistemologia feminista; gênero; ensino de ciências e biologia.

${ }_{1}^{1}$ Mestre em Educação. Docente no curso de Pedagogia da Faculdade FAEL da Lapa Paraná - Brasil. E-mail: andréacbruel@gmail.com.

2 Mestranda no Programa de Pós Graduação em Ensino de Ciências e Educação Matemática, Universidade Estadual de Ponta Grossa - Paraná - Brasil. E-mail: aninha_santos1997@hotmail.com.

3 Doutora em Ensino de Ciências e Educação Matemática. Docente do curso de licenciatura em Ciências Biológicas e do Programa de Pós-Graduação em Ensino de Ciências e Educação Matemática e de Educação Universidade Estadual de Ponta Grossa - Paraná - Brasil. E-mail: bettina_heerdt@yahoo.com.br.

GT 02 - Epistemologia feminista: reflexões no Ensino de Ciências 


\title{
Speeches of students of basic education regarding gender, science and human fertilization
}

\begin{abstract}
Gender analyzes in science evidence androcentric knowledge, which excludes and inferiorizes women, as in the content of human fertilization. In the teaching of Science and Biology, gender discrimination can be reaffirmed. The objective of the research is to analyze the discourse of Basic Education students, when representing the process of human fertilization. The research is qualitative, the data comes from the investigation by Santos and Heerdt (2019), through the construction and application of a Didactic Unit (UD). The data were analyzed by discourse analysis, using feminist epistemologies to infer their meanings. We found that the students describe the process a equality form, highlighting both gametes, citing aspects of recent research and contributions from the female body, discussed during the UD, but fall into stereotypes, when representing fertilization in the form of marriage. The speeches are controversial, however, the possibility of transgressing the knowledge imposed as truth and criticized by feminist epistemologies appears in the speeches.
\end{abstract}

Key words: feminist epistemology; gender; science and biology teaching.

\section{Introdução}

Compreendemos a ciência a partir dos estudos das epistemologias feministas, como um empreendimento masculino, não neutra, que produz conhecimentos androcêntricos que não respondem aos interesses emancipatórios das mulheres (MAFFIA, 2015; SARDENBERG, 2002). Gênero, por sua vez, se constitui como "um objeto teórico para as investigações e reflexões feministas [...], um instrumento de análise" (SARDENBERG, 2002, p. 6).

As análises de gênero na ciência evidenciam conhecimentos que foram construídos numa perspectiva androcêntrica, excluindo e inferiorizando as mulheres. Na Biologia, conteúdos como o de fecundação humana estão permeados por discriminações e preconceitos que foram evidenciados pela crítica feminista (KELLER, 2006; MARTIN, 1991; SCHIEBINGER, 2001). No momento do ensino deste conteúdo, 
preconceitos e discriminações podem ser transmitidos e reafirmados, pois as questões de gênero são, muitas vezes, naturalizadas e podem passar despercebidas.

Posto isso, o objetivo desta pesquisa é analisar os discursos de alunos/as da Educação Básica ao representarem o processo de fecundação humana durante a Unidade Didática (UD) intitulada "A visibilidade do ovócito no processo de fecundação" (SANTOS; HEERDT, 2019). Buscamos investigar quais discursos são recorrentes, discursos que ocorrem eventualmente, e discursos invisibilizados na fala dos/as alunos/as. As análises estão ancoradas pelas epistemologias feministas, para as possíveis inferências nos significados desses discursos.

\section{Universo da Pesquisa}

Esta pesquisa é de natureza qualitativa e feminista, "concentrase nas diversas situações femininas, problematizando-as, e também nas instituições que compõem essas situações" (OLESEN, 2006, p. 220). Ainda segundo a autora, não se pode falar em um único feminismo, pois existem feminismos diversos, por isso aqui utilizamos o termo feminismos, no plural.

Para Longino (2008) todo o conhecimento produzido é situado, pois o sujeito produtor do conhecimento é corporificado, ou seja, é influenciado por diversos fatores como o contexto social, histórico e cultural no qual está inserido. Assim, nos colocamos nesta pesquisa como mulheres cisgênero, brancas e parda, feministas, professoras e envolvidas emocionalmente e profissionalmente com as questões de gênero, feminismos na ciência e na sociedade.

Os/as participantes da pesquisa são alunos/as do $2^{\circ}$ ano do Ensino Médio de uma escola Pública no Paraná, Brasil, com idade entre 16 e 18 anos. Os dados desta pesquisa são provenientes da investigação de Santos e Heerdt (2019; 2020, no prelo), com o objetivo de investigar 
as compreensões e promover reflexões dos/as alunos/as da educação básica, as autoras construíram e aplicaram uma Unidade didática (UD) articulando Natureza da Ciência (NdC), gênero e fecundação humana.

As vídeo gravações que se constituem como dados para as análises dos discursos, são produções advindas de uma das atividades finais da intervenção, na qual os/as alunos/as representaram o processo de fecundação humana, levando em consideração tudo o que havia sido debatido no transcorrer desta intervenção. $O$ projeto de pesquisa utilizado para a coleta de dados foi avaliado e aprovado pelo comitê de ética (COEP) sob o parecer número 2.446.856. A fim de manter o anonimato, os/as alunos/as foram nomeados/as de letra A correspondendo a aluna/o, seguido de um número (exemplo: 01) estabelecido para os discursos, e por fim a letra "a" para meninas ou a letra "o" para meninos, conforme eles/elas se identificaram (exemplos: A01o, A02a).

Para a análise dos dados empregamos aspectos da análise de discurso seguindo algumas recomendações de Gill (2012), dentre eles: formular questões de pesquisa; selecionar e transcrever os dados; ler ceticamente os dados transcritos; codificar os dados; analisar procurando padrões e variabilidade e descrever minuciosamente. Vale ressaltar que em todos os momentos da análise os referenciais das epistemologias feministas estavam direcionando o nosso olhar e orientando nossas interpretações e inferências.

Acreditamos que por meio da análise do discurso seja provável que novos olhares e leituras da realidade aconteçam, possibilitando elucidar ideologias e valores presentes nos discursos proferidos pelos sujeitos que se encontram imersos em organizações culturais construídas com base em linguagens simbólicas, e de regras, que de alguma forma regem as práticas sociais (GABRIELLI, 2007).

As epistemologias feministas contribuíram para a desconstrução dos fundamentos da ciência moderna, como a neutralidade e objetividade (SARDENBERG, 2002), e evidenciaram que o 
conhecimento produzido pela ciência expressa um ponto de vista androcêntrico, ou seja, "o do homem adulto, branco, dono, capaz" (MAFFÍA, 2014, p. 104, tradução nossa).

Desconstruções que tiveram em parte as suas premissas nas críticas realizadas pelas epistemologias feministas, muito embora tenham iniciado por interrogações em âmbito político voltadas primeiramente ao que diz a respeito à discriminação em relação às mulheres na base social da ciência, do preconceito androcêntrico nas ciências sociais e na Biologia, o que incorreu em volumosa interpelação das alegações feitas ao pensamento ocidental moderno. Dessa forma, as críticas tacitamente desafiam as estruturações teóricas em que as perguntas iniciais foram elaboradas, e segundo as quais poderiam ser questionadas (HARDING, 1993).

Em conformidade com Anderson (2001) a crítica feminista historiciza a ciência, quando converge para o reconhecimento de que gênero tornou-se um instrumento de análise, uma categoria de construção do conhecimento, um objeto teórico de investigação para as epistemologias feministas (SARDENBERG, 2002), é por meio das análises de gênero que se evidencia o androcentrismo presente na construção da ciência.

Especificamente na área da Biologia, as críticas feministas a ciência, revelaram diversos conteúdos que utilizavam características biológicas para reforçar e naturalizar discriminações e preconceitos das esferas social e cultural. A respeito dos estudos de concepção humana/fecundação, Maffía (2014) exemplifica ideais de Platão e de Aristóteles, que demonstram a construção androcêntrica desse conhecimento, o homem era o gerador da concepção e a mulher era apenas o receptáculo, a mulher carecia de um calor que só existia no homem. Para Aristóteles as diferenças entre homens e mulheres demonstravam a hierarquia "natural" existente e justificavam as relações de poder entre homens e mulheres, senhores e escravos, adultos e crianças. 
Autoras como Martin (1991) e Schiebinger (2001) também discutem as descrições androcêntricas da fecundação humana, as autoras apontam que o ovócito, porção feminina, é invisibilizado nas descrições do processo, e recebe características como lento e passivo, sendo mero receptor das ações do espermatozoide, que tem destaque nas descrições e é caracterizado como rápido, ativo e protagonista do processo de fecundação. As críticas feministas abriram espaço para novos estudos, que descrevem o papel ativo do ovócito para a fecundação e demonstram que ambos os gametas trabalham juntos para que o processo ocorra (SCHATTEN; SCHATTEN, 1983).

No momento do ensino, essas discriminações podem ser transmitidas e reafirmadas, por meio dos discursos de docentes, de livros didáticos e vídeos, que não consideram as novas pesquisas, descrevendo os gametas de forma desigual e não citando as contribuições do organismo feminino na fecundação (NETTLETON, 2015; SWIECH; SANTOS; HEERDT, 2019).

Pensando na influência do ambiente escolar e do Ensino de Ciências como processo formativo na vida dos/as alunos/as, é necessário intervir nesse meio, para que se construa uma compreensão mais equânime de ciência e de seus conteúdos e para "proporcionar condições de ensino que favoreçam uma aprendizagem liberta de discriminações de gênero" (BATISTA et al., 2011, p. 4-5).

\section{Diálogos acerca dos discursos produzidos}

Para a atividade os/as 15 alunos/as participantes se organizaram em cinco grupos que representaram a fecundação humana de formas variadas, nomeamos os grupos de A, B, C, D e E. Vale ressaltar que analisamos os discursos escritos dos/as alunos/as, a linguagem corporal, visto que houve um grupo que fez a representação por meio de um teatro, mas não analisamos as imagens produzidas. 
As alunas A01a, A02a, A03a E A04a e os alunos A05o, A06o, A07o optaram por desenhar no quadro e explicar oralmente o processo de fecundação. Os/a alunos/a A08o, A09o, A10a, A11o optaram por representar a fecundação em forma de teatro. As/o alunas/o A12a, A13a, A14o explicaram oralmente o processo de fecundação. A aluna A15a realizou a leitura de um texto produzido por ela e colegas que estavam no grupo para explicar o processo de fecundação humana.

$\mathrm{Na}$ etapa de codificação dos discursos destacamos quais discursos são: recorrentes, eventuais e invisibilizados pelos/as alunos/as. Os trechos dos discursos que descreviam o ato sexual não foram analisados, apenas os de fecundação humana.

\section{Discursos recorrentes}

- Ditos da Relação de interdependência entre os gametas

Foram recorrentes nos discursos dos/as alunos/as, citações da relação de interdependência entre os gametas, como nos trechos abaixo:

"[...] Querendo mostrar os dois lados, que os dois são importantes" (A03a).

"O que a gente quis retratar é que existe uma relação de interdependência dos dois lados. [...] Não acontece nada se um ou o outro não existir" (A01a).

“O processo ocorre entre dois gametas sendo assim, a ajuda é mútua. [...] Os gametas trabalham juntos para que isso ocorra" (A15a).

Durante a UD, foram apresentadas e discutidas descrições que invisibilizavam o papel do ovócito no processo de fecundação, refletindo com os/as alunos/as acerca dos papeis sociais de gênero que foram transpostos aos gametas ao longo da construção do conhecimento de fecundação humana.

As relações de interdependência foram recorrentes nos discursos das meninas, porém não aparecem nos discursos dos meninos. A partir dos discursos, percebemos que as meninas procuram deixar claro a 
importância de ambos os gametas, sem enfatizar um sobre o outro, acreditamos que elas, como mulheres, foram submetidas historicamente a uma posição de submissão, que foi transposta aos gametas, e quando percebem isso, procuram proferir um discurso equânime, sem tomar a relação de poder para si.

No entanto, para Spanier (apud SCHIEBINGER, 2001) a noção de igualdade entre o óvulo e o espermatozoide é falaz, o que pode invisibilizar a contribuição do óvulo, como o gameta maior que fornece organelas como a mitocôndria e os ribossomos, a membrana celular e proteínas decisivas ao desenvolvimento do zigoto.

No caso dos alunos homens, apesar de citarem algumas contribuições do ovócito, como será demonstrado adiante, não citam como uma relação interdependência, e novamente refletimos quanto à posição histórica do homem de detentor do poder, que foi transposta para os gametas. Para os meninos é mais difícil abandonar uma posição de poder, que é confortável, para pensar numa relação na qual esse poder seja "compartilhado", mesmo que seja no âmbito dos gametas.

- Ditos das enunciações machistas e desiguais

Também foi recorrente nos discursos das meninas críticas a descrições machistas e desiguais do processo de fecundação, como podemos observar nos trechos:

"Bom aí, aqui nesse segundo desenho a gente tá querendo retratar, é... a parte que na verdade eles [os cientistas ou as descrições] não mostram [...]" (A01a, grifo nosso).

"É muito importante que o conceito de fecundação seja repensado, não sendo levado para o lado machista. [...] O espermatozoide é visto com uma ideia humana, e retratado em muitos lugares assim, com uma visão de superioridade com relação ao óvulo, como ocorre na sociedade, uma visão machista. Mas o desejo de realmente conhecer a forma como o processo ocorre muda esse estereótipo. A mudança começa pela busca de conhecimento" (A15a). 
"E aqui é o que eles [os cientistas ou as descrições] só mostram, né? Que é o... espermatozoide entrando no óvulo sem... e ele ali esperando. Só como se fosse a parte do espermatozoide e o óvulo ali..." (A02a, grifo nosso)

Durante o processo formativo os/as alunos discutiram e refletiram acerca dos estereótipos de gênero na sociedade, as desigualdades e relações de poder entre homens e mulheres. Além disso, ao trazer essas reflexões para a ciência, analisaram descrições do processo de fecundação humana, desde Aristóteles até pesquisas recentes, refletindo a construção de um discurso androcêntrico deste conhecimento.

No discurso das alunas é possível perceber a crítica à invisibilidade das ações do ovócito nas descrições, quando afirma que "é... a parte que na verdade eles [os cientistas ou as descrições] não mostram" (A01a, grifo nosso), quando se refere ao auxílio do ovócito direcionando o espermatozoide para a penetração. A aluna A02a direciona sua crítica à ênfase dada ao espermatozoide nas descrições que destacam suas ações, enquanto o ovócito apenas espera.

Essas descrições criticadas pelas alunas não foram apenas as debatidas durante o processo formativo, mas também dos livros didáticos que muitas vezes esses/as alunos/as tem contato na escola. Swiech, Santos e Heerdt (2019) ao analisarem nove livros didáticos aprovados pelo PNLD 2018, evidenciam que todas as obras em algum momento enfatizam o espermatozoide no processo e algumas obras utilizam adjetivos e metáforas para reforçar as ações do espermatozoide e a passividade do ovócito, como "pioneiro" ao se referir ao espermatozoide e "impelido" ao se referir ao ovócito.

A aluna A15a, critica a atribuição de características humanas aos gametas e a visão machista transmitida em muitas descrições do processo, que foram debatidas durante a UD. Martin (1991) critica e aponta descrições e metáforas que colocam o ovócito como inferior ao espermatozoide, como ocorreu na pesquisa de Schatten e Schatten (1983), que apesar de pesquisarem o papel ativo deste para a 
fecundação, acabam comparando-o com a "Bela adormecida", a autora também exemplifica descrições em que os espermatozoides são caracterizados como fortes, corajosos e lutadores, características que não pertencem as células, mas são da esfera humana, como a aluna critica em seu discurso.

Keller (2006) reflete em seu artigo, que por muito tempo não se conhecia as atividades do ovócito, por isso as descrições, embora sexistas, acabavam sendo consistentes, pois os experimentos demonstravam a motilidade e os mecanismos de ação do espermatozoide na fecundação, enquanto o mecanismo das atividades do ovócito ainda não havia sido encontrado. Agora, novas pesquisas destacam e descrevem o papel ativo do ovócito, e como Keller (2006, p. 19) afirma "pode-se dizer que os pesquisadores os encontraram porque procuraram por eles", o que vai de encontro com a reflexão feita no discurso da aluna A15a, de que se buscarmos "compreender como realmente ocorre o processo", fora das lentes machistas e androcêntricas, podemos repensar a fecundação humana e retirar esse conhecimento da ignorância, a que foi por décadas, imposto pela ciência.

- Ditos do organismo feminino na fecundação

Foi recorrente nos discursos dos/as alunos/asas contribuições do organismo feminino para a fecundação, como se observa nos trechos a seguir:

“Eu vou ser o óvulo. O [aluno A09o] ele tá como papel da contração, no.... que ajuda o óvulo... o espermatozoide a chegar no óvulo" (A08a, grifo nosso).

“... Como você explicou o útero ele solta um muco, né? que direciona o... espermatozoide e faz com que ele consiga penetrar o óvulo" (A01a).

"o útero, isso! Ele libera o muco pra que... pra evitar que os espermas eles batam na...naquele negócio da vagina... nas paredes da vagina [...] o útero vai fazer contrações para que o esperma chegue até o óvulo" (A12a). 
"[...] Que, se não fosse pelo muco o esperma ele ia ficar tentando entrar em outros lugares, porque ele não tem olho, né?" (A12a).

"Os ovócitos e o endométrio liberam um produto químico que é compatível a um receptor presente na cabeça dos espermatozoides, atraindo-os para o óvulo" (A15a).

Nos discursos, apesar de algumas confusões conceituais, é possível perceber que os/as alunos/as citam o muco uterino que auxilia no caminho dos espermatozoides, evitando que eles penetrem nas paredes uterinas ou da vagina, e o papel das contrações uterinas que "guiam" os espermatozoides, uma aluna cita também a liberação de substâncias químicas, pelo endométrio, que atraem os espermatozoides.

Essas contribuições, muitas vezes, não estão presentes nos discursos dos/as docentes ao ensinar o processo de fecundação humana, até mesmo porque muitas das ferramentas utilizadas para o ensino não apresentam essas contribuições, como os livros didáticos, por exemplo (SWIECH; SANTOS; HEERDT, 2019), deste modo, esse conhecimento fica na ignorância, desconhecido, a questão é o que essa ignorância tem a nos ensinar?

Os/as alunos/as passaram por um processo formativo, no qual, debateram as contribuições do organismo feminino para a fecundação. Esses debates e discussões possibilitaram a construção dos conhecimentos mencionados por eles/as nos discursos.

- Ditos de pesquisas recentes

Há recorrência no discurso dos/as alunos/as no que se refere aos discursos produzidos em pesquisas recentes como podemos observar a seguir:

"[...] Sobre a... microvilosidade que ajuda o espermatozoide a ter uma orientação pra poder entrar no... no óvulo" (A05o).

"[...] Foi explicado que... o óvulo... o espermatozoide ele se movimenta daquela forma assim...é... não é direto no óvulo. Então assim, ele vai ficar rodando em volta e eternamente se... não... tivesse aquele mecanismo de... de orientação, né" (A09o). 
"Daí.. logo que chega até o útero... o óvulo na verdade, vai acontecer isso daqui né, [...] que a microlo... microvilosidade, ele vai ajudar na direção do esperma até chegar ao óvulo [...]" (A140).

“Encontrando o óvulo, com a ajuda das microvilosidades deste, o espermatozoide é capturado e é orientado para a penetração. [...] Ambos possuem moléculas adesivas em sua superfície que permitem a ligação dos dois. Quanto mais movimento, mais preso fica ao óvulo" (A15a).

Os/as alunos/as mencionaram em seus discursos a ação das microvilosidades, que orientam o espermatozoide para a penetração, informação descrita na pesquisa de Gerald Schatten e Heide Schatten, em 1983. Uma aluna descreveu também a presença de moléculas adesivas na superfície dos gametas que permite à aderência destes, descoberto por meio de estudo realizado por pesquisadores da Universidade Johns Hopkins (MARTIN, 1991). Durante o processo formativo, mencionamos aos/as alunos/as alguns dados dessas pesquisas.

Essas informações, apesar de estarem presentes na literatura, ainda são pouco mencionadas nas escolas, e não são contempladas em livros didáticos, por exemplo (SWIECH; SANTOS; HEERDT, 2019).

Porém, como afirma Martin (1991), mesmo em novas pesquisas os/as pesquisadores/as podem recair em estereótipos, citando por exemplo, a ação do ovócito restrita apenas a suas partes, e não ao todo. Analisando os discursos dos/as alunos/as percebemos que, citando as pesquisas recentes, recaem em um discurso desigual, restringindo a ação do óvulo à microvilosidade, pois atribuem a partes do óvulo, e não ao óvulo em si o papel ativo na fecundação (MARTIN, 1991).

\section{Discursos eventuais}

- Ditos da fecundação como casamento

Eventualmente aparecem nos discursos das/os alunas/os a fecundação como casamento, como o que é verificado nos trechos: 
“você óvulo, aceita se casar com esse espermatozoide?" (A11o).

$$
\text { "sim, aceito" (A09o). }
$$

"Então assim, [o aluno A11o] fez o papel da orientação, que daí ele perguntou se ele queria, é... se eu [o óvulo] queria casar..." (A09o, grifo nosso).

"[...] para que o óvulo aceite a... o esperma... a se "casarem"" (A14o).

Um dos grupos de alunos/as optou por representar o processo de fecundação humana por meio de uma cena de casamento. Um dos alunos (A08o) fez o papel de óvulo, outro aluno (A11o) fez o papel de orientação, que inferimos corresponder as microvilosidades, outra aluna representava o espermatozoide (A10a) e o aluno A09o fazia o papel da contração uterina, que levou o espermatozoide (A10a) até o altar, onde o "óvulo" e a "orientação" aguardavam. Deste contexto, surgiram os discursos acima: "você óvulo, aceita se casar com esse espermatozoide?" (A11o), que responde: "sim, aceito". (A09o), e os dois se abraçam e encerram o teatro.

Na representação os/as alunos/as demonstram as contribuições do organismo feminino, por meio das contrações uterinas, e citam o papel de orientação das microvilosidades para a penetração. Os/as alunos também procuram mostrar o "consenso" do ovócito para permitir a penetração.

O grupo D fez uma explicação oral do processo de fecundação, e em determinado momento o aluno A14o usa a metáfora do casamento para se referir ao momento da fecundação "[...] para que o óvulo aceite a... o esperma... a se "casarem"" (A140).

Embora os/as alunos/as tentem demonstrar e descrever o processo de fecundação humana de forma equânime, quando representam este como forma de casamento, acabam recaindo em estereótipos e apresentando discursos semelhantes aos que foram analisados durante a UD, atribuindo características sociais e culturais humanas, às células, aos gametas, situando o óvulo como uma "noiva" e o espermatozoide como o "noivo". 
Para Martin (1991) as imagens estereotípicas podem também encorajar que se imagine que a interação entre o óvulo e o esperma - um óvulo fertilizado - é o resultado de uma ação "humana" deliberada no nível celular. Independentemente das intenções do casal humano, nesta "cultura" microscópica uma "noiva" celular (ou fêmea fatal) e um "noivo" celular (sua vítima) fazem um bebê celular.

\section{Discursos invisibilizados}

- Não ditos: fecundação como reflexo de namoro ou violação e gametas estereotipados

Dirigimos o nosso olhar e análises também para os discursos que não foram proferidos pelos/as alunos/as, mas que são apontados pelo referencial teórico da pesquisa, buscando compreender o que a ausência desses discursos revela.

Analisando historicamente a construção do conhecimento de fecundação humana, é comum encontrarmos descrições que apresentavam ovócito passivo e espermatozoide ativo, até a década de 1970 (SCHIEBINGER, 2001). Porém, mais que papeis ativo e passivo os gametas eram estereotipados, o espermatozoide era quem percorria uma "jornada arriscada" em busca do óvulo, dotado de agilidade e força enquanto o ovócito aguardava passivamente, como a Bela Adormecida, o beijo do seu companheiro (MARTIN, 1991; SCHIEBINGER, 2001). Mais tarde, o avanço de pesquisas como as de Schatten e Schatten (1983) que investigavam o papel ativo do ovócito na fecundação, trouxeram à tona outra narrativa, a do ovócito masculinizado, que ao ser descrito como ativo, torna-se também agressivo. 
Na UD analisamos alguns vídeos disponíveis no Youtube com animações representando o processo de fecundação humana. Embora os vídeos não tenham caráter científico, podem ser utilizados como ferramenta didática por docentes. Um dos vídeos, representava o espermatozoide com uma postura agressiva, tentando penetrar o ovócito a força, utilizando, por exemplo, uma bomba para romper a estrutura do ovócito. Refletimos com os/as alunos/as o impacto de discursos como esse, nas salas de aula, que acabam por normalizar a violência contra a mulher e até mesmo o estupro, colocando isso na área "natural" / "biológica", como se até mesmo as células dos homens tivessem comportamentos agressivos e as das mulheres comportamentos submissos.

Em outro vídeo, o espermatozoide levava flores para o ovócito e este o deixava "entrar", representando a fecundação como se fosse uma conquista, e transpondo papeis e situações sociais e culturais de homens e mulheres, para as células. Da mesma forma que ocorre nesses vídeos e animações, muitas vezes nós docentes e cientistas utilizamos metáforas, figuras e linguagem mais próxima da cultural, como afirma Schiebinger (2001, p. 274) "as metáforas não são dispositivos inocentes usados para temperar textos", portanto, se formos utilizá-las na linguagem, que seja de forma equânime, e não para cimentar estereótipos.

Os discursos da fecundação como reflexo de namoro ou violação foram invisibilizados/ignorados pelos/as alunos/as.

\section{Considerações Finais}

Neste trabalho, nos propusemos a analisar o discurso de alunos/as da educação básica ao representarem o processo de fecundação humana durante a UD "A visibilidade do ovócito no processo de fecundação" (SANTOS; HEERDT, 2019). Buscamos investigar quais discursos foram recorrentes, eventuais e invisibilizados pelos/as alunos/as. 
Foram recorrentes, discursos que apresentavam críticas às descrições que não mostravam o processo de forma equânime; que descreviam o processo de forma equânime, citando a relação de interdependência entre os gametas; que citavam as contribuições do organismo feminino na fecundação e que apresentavam dados de pesquisas recentes. Foi eventual, o discurso que descreveu a fecundação como casamento. Dos discursos invisibilizados pelos/as alunos/as, pontuamos os que descreviam a fecundação como reflexo de namoro ou violação, e os gametas de forma estereotipada.

É importante situarmos os/as alunos/as que participaram do processo formativo. Estes/as se mostraram abertos as discussões, expondo suas ideias e pensamentos, colocando questionamentos e reflexões ao decorrer do processo. No transcorrer das analises, foi possível perceber que o discurso do processo formativo, que estava embasado nos referenciais de gênero e ciência, permitiu que pensassem em relação a verdades (im)postas pela ciência de forma a transgredir, a poder pensar diferente, a duvidar das certezas, o que de certa forma ficou evidente nos discursos ditos e não ditos pelos/as alunos/as.

Nosso objetivo não é fornecer respostas, mas gerar questionamentos. As questões que gostaríamos de propor ao final deste artigo são referentes ao ensino de ciências: qual tem sido o discurso dos/as docentes em sala de aula, ao ensinar a fecundação humana? De que forma temos utilizado as metáforas para moldar o pensamento dos/as nossos/as alunos/as quanto aos papeis de gênero? Como afirma Martin (1991, p. 11), é preciso acordar das metáforas e perceber se "estamos projetando imagens culturais sobre o que estudamos", pois os discursos docentes, influenciam o discurso dos/as alunos/as.

\section{Referências}

ANDERSON, Elizabeth. Feminist Epistemology and Philosophy of Science. In: Edward N. (ed.) ZALTA. The Stanford Encyclopedia of Philosophy (Spring 2011 edition). online: Disponível em: 
http:/ / plato.stanford.edu/archives/spr2011/entries/feminismepistemology/.

BATISTA, Irinéia de Lourdes; TOREJANI, AszuenTsuyako do Carmo; HEERDT, Bettina; LUCAS, Lucken Bueno; OHIRA, Márcio Akio; CORRÊA, Maria Lúcia; BARBOSA, Roberto Gonçalves; BASTOS, Vinícuis Colussi. Gênero Feminino e Formação de Professores na Pesquisa em Educação Científica e Matemática no Brasil. Atas Encontro Nacional de Pesquisa em Educação em Ciências, 8., Campinas, SP, Brasil, 2011.

FLICK, Uwe. Introdução à metodologia de pesquisa: um guia para iniciantes. Tradução de Magda Lopes. Porto Alegre: Penso, 2013.

GABRIELLI, Cassiana Panissa. Análise crítica do discurso e teoria feminista: diálogos frutíferos. In: Seminário Nacional Mulher e Literatura; Anais [...], 12, 3, Ilhéus, 2007. Ilhéus: UESC.

GILL, Rosalind. Análise de discurso. In: BAUER, M. W.; GASKELL, G. (Ed). Pesquisa qualitativa com texto, imagem e som um manual prático. Tradução de Pedrinho A. Guareschi. 10. ed. Petrópolis: Vozes, 2012.

KELLER, Evelyn Fox. Qual foi o impacto do feminismo na ciência? Cadernos Pagu, n. 27, p. 13-34, 2006.

LONGINO, Helen. The social dimensions of scientific knowledge. Stanford Encyclopedia of Philosophy, 2008. Recuperado de https:/ / plato.stanford.edu/entries/scientific-knowledge-social/.

MAFFÍA, Diana. Epistemología feminista: La subversión semiótica de las mujeres em la ciencia. Revista Feminismos, v. 2, n. 3, 2014.

MARTIN, Emily. The Egg and the Sperm: How Science Has Constructed a Romance Based on Stereotypical Male-Female Roles. Signs: Journal of Women in Culture and Society, v. 16, n. 3, Spring 1991.

NETTLETON, Pamela Hill. Brave Sperm and Demure Eggs: Fallopian Gender Politics on YouTube. Feminist Formations, v. 27, n. 1, p. 25-45, 2015. 
OLESEN, Virginia L. Os feminismos e a pesquisa qualitativa neste novo milênio. In: DENZIN, Norman K.; LINCOLN, Yvonna S. O planejamento da pesquisa qualitativa: teorias e abordagens. Tradução de Sandra Regina Netz. Porto Alegre: Artmed, 2006. 423 p.

SANTOS, A. P. O. dos; HEERDT, B. Unidade Didática: a visibilidade do ovócito no processo de fecundação humana. Experiências em Ensino de Ciências, v. 14, n. 2, 2019.

SARDENBERG, Cecilia Maria Bacellar. Da Crítica Feminista à Ciência a uma Ciência Feminista? In: COSTA, A. A. A.; SARDENBERG, C. M. B. (Org.). Feminismo, Ciência e Tecnologia. Salvador: REDOR/NEIMFFCH/UFBA, 2002.

SCHATTEN, Gerald; SCHATTEN, Heide. The Energetic Egg. The Sciences, v. 23, n. 5, p. 28-35, sept./oct. 1983.

SCHIENBINGER, Londa. O feminismo mudou a ciência? Tradução de Raul Fiker. Bauru: Edusc, 2001.

SWIECH, Mayara Juliane; SANTOS, Ana Paula Oliveira dos; \& HEERDT, Bettina. Processo de fecundação humana: uma análise de gênero nos livros didáticos. Atas do XII Encontro Nacional de Pesquisa em Educação em Ciências, Natal, RN, Brasil, 12, julho, 2019. 